\title{
A CasaDuna de Atafona - Arte em contexto erosivo
}

\author{
Julia Naidin ${ }^{1}$ e Fernando Codeço²
}

Resumo: Neste artigo buscamos indicar o contexto histórico e socioambiental da praia de Atafona em São João da Barra (RJ) onde se situa o centro de arte CasaDuna e refletir sobre a metodologia adotada pelo mesmo, bem como sobre as implicações políticas e estéticas de algumas ações artísticas contextuais realizadas entre 2017 e 2019.

Palavras-chave: arte contextual, erosão marinha, Atafona, CasaDuna

\section{CasaDuna - Art in erosive context}

\begin{abstract}
In this article we seek to indicate the historical and socio-environmental context of the Atafona beach in São João da Barra (RJ) where the CasaDuna art center is located and reflect on the methodology adopted by it, as well as on the political and aesthetic implications of some actions on contextual art carried out between 2017 and 2019.
\end{abstract}

Keywords: contextual art, marine erosion, Atafona, CasaDuna

1 Pesquisa metodologias de ação na arte contemporânea como Pós-doutorado no programa de Políticas Sociais na UENF. Doutora em Filosofia na UFRJ, com bolsa PDSE na EHESS - Paris, desenvolvendo trabalhos sobre a filosofia ético-política de Michel Foucault. Desde 2017, coordena e produz na CasaDuna - centro de arte, pesquisa e memória de Atafona e é atriz no Grupo Erosão. Universidade Estadual do Norte Fluminense (UENF). E-mail: jnaidin@gmail. com. ORCID: https://orcid.org/0000-0002-7729-0793. Lattes iD: http://lattes.cnpq.br/8846085851544071. São João da Barra, Brasil.

2 Artista plástico, pesquisador e diretor de teatro, vive atualmente na praia Atafona, município de São João da Barra, onde coordena a "CasaDuna - Centro de Arte, Pesquisa e Memória de Atafona". Dirige também o "Grupo Erosão de teatro e artes visuais". Está cursando o doutorado em artes cênicas pela UNIRIO em cotutela com a UPJV, Amiens, França. Universidade Federal do Estado do Rio de Janeiro (UNIRIO) e Université de Picardie Jules Verne (UPJV). E-mail: fernandocodeco@gmail.com. Lattes iD: http://lattes.cnpq.br/9001135551476935. São João da Barra, Brasil 


\section{Introdução}

A CasaDuna - Centro de arte, pesquisa e memória de Atafona é uma residência de arte instalada na praia de Atafona, localizada no município de São João da Barra, litoral norte do estado do Rio de Janeiro. A região, próxima ao delta do rio Paraíba do Sul, sofre há mais de cinquenta anos um intenso processo de erosão costeira. Este importante rio, que passa pelos estados mais populosos e industriais do Brasil (São Paulo, Minas Gerais e Rio de Janeiro) até encontrar o Oceano Atlântico, teve, nas últimas décadas, mais de $2 / 3$ de seu fluxo desviado, além de inúmeras outras interferências humanas, tais como poluição e desmatamento da mata ciliar. Este fato, segundo cientistas e ambientalistas, foi determinante para a intensificação do processo erosivo em Atafona.

A CasaDuna surge de um desejo de habitar e trabalhar neste território rico em história, cultura e biodiversidade e em pleno processo de degradação socioambiental. Nossa percepção é a de que falar de Atafona é urgente, não só para a vida das comunidades locais, que sofrem há décadas com as consequências da gestão irresponsável dos recursos naturais, mas também para pensar de modo mais amplo sobre a atual crise civilizatória global a partir da perspectiva da experiência brasileira. A paisagem de ruínas da praia de Atafona é a imagem brutal do "estado das coisas" no Brasil de Jair Bolsonaro, um mundo onde os valores humanos mais básicos foram colapsados. Se é verdade que a crise em que nos encontramos hoje tem raízes históricas bem anteriores à recente virada política ultraconservadora, é também verdade que houve grandes avanços nas políticas sociais e culturais no período dos governos do Partido dos Trabalhadores ${ }^{1}$. Mesmo que naquele período o modelo desenvolvimentista e extrativista não tenha sido colocado em xeque, havia a esperança de que com o aumento de investimentos em educação, pesquisa, políticas de distribuição de renda e reparação social poderíamos encontrar soluções coletivas e democráticas para os nossos históricos problemas infraestruturais. Havia sobretudo o respeito e a valorização dos institutos de pesquisa, de preservação do meio ambiente, das universidades e da produção cultural. Hoje vivemos uma verdadeira guerra contra qualquer inciativa crítica no âmbito da produção cultural e da pesquisa acadêmica e científica, a perseguição política e o assassinato de lideranças indígenas e comunitárias, a desestruturação

1 O Partido dos Trabalhadores esteve a frente da presidência da república no período que vai de 2003 a 2016, (Com Lula de 2003-2012, e com Dilma de 2012, até sofrer um golpe parlamentar em 2016). 
dos órgãos de proteção ambiental e a venda escancarada de nossas riquezas naturais e empresas estratégicas.

No início de 2017, nos mudamos para Atafona com o intuito de funcionar como um coletivo e uma residência dedicados à produção de arte, pesquisa e memória neste território. Criamos um espaço para abrigar artistas interessados na produção contemporânea com foco na relação da arte contextual. Fundamos um grupo de teatro e passamos a funcionar também como uma produtora cultural, elaborando projetos de arte e educação. No decorrer do trabalho, constituímos um acervo com materiais históricos, contribuindo para a produção de memória oral e visual sobre o local. Hoje fazemos parte como colaboradores externos de projetos de extensão que atuam em campos interdisciplinares na UENF e na UNIFESP2; e contamos com uma rede de artistas, pesquisadores, produtores e entidades culturais que colaboram com nossos projetos ${ }^{3}$. Neste contexto, interessa-nos desenvolver produções artísticas como proposta de reflexão para acionar outros modos de relação com o território e questionar as linguagens da arte fora dos lugares reservados a ela nos circuitos institucionalizados da arte contemporânea, como galerias e museus.

O processo de destruição em Atafona é complexo: ele é ao mesmo tempo geológico - a erosão costeira é o fenômeno do mar corroendo os sedimentos do solo e destruindo as fundações das construções; político - pois existem decisões políticas em jogo tanto no processo da erosão quanto no impasse em relação a um prognóstico de ação para a população afetada por essa situação; antropológico - pois existe um modo de vida que vai gradualmente sendo transformado no decorrer deste processo; e ecológico - uma vez que, junto com a vida dos habitantes humanos, uma série de outros ecossistemas que se sustentam em rede se alteram com as transformações do ambiente.

Levando em conta esta interdisciplinaridade, buscamos refletir sobre alguns aspectos do trabalho que estamos desenvolvendo em Atafona: 1) Indicar o contexto histórico e socioambiental no qual nos inserimos, visando um trabalho de produção e pesquisa em arte que assume uma perspectiva

2 Participamos dos projetos Observatório da Dinâmica Costeira e Sentinelas das praias do Departamento de Ciências do Mar da UNIFESP e do projeto de extensão Teia Universitária das Artes, do Centro de Ciências do Homem da UENF.

3 A lista de artistas e colaboradores da CasaDuna encontra-se disponível em nosso site: https://www.casaduna.org/. 
crítica com relação ao modelo hegemônico de desenvolvimento neoliberal e suas consequências catastróficas; 2) Uma reflexão sobre a metodologia adotada de pesquisa-criação como arte contextual; 3 ) Um relato crítico reflexivo sobre algumas de nossas atividades realizadas neste período de trabalho entre os anos de 2017 e 2019; 4) E, por fim, uma conclusão sobre as possíveis significações estéticas e políticas do trabalho realizado até aqui em sua relação com as discussões atuais sobre arte, decolonialismo e mudanças climáticas.

\section{Contexto histórico e socioambiental}

Atafona e as ilhas da Convivência e do Peçanha, localizadas no delta do rio Paraíba do Sul, foram historicamente ocupadas por uma comunidade de pescadores ${ }^{4}$. A maior parte desta comunidade vivia nas ilhas. No entanto, a partir do fim do século XIX, Atafona começa a ser frequentada também por veranistas oriundos principalmente da rica e populosa cidade vizinha Campos dos Goytacazes. Ao longo século XX, a prática da vilegiatura em Atafona por campistas se desenvolve, atraindo os pescadores e comerciantes locais, que passam oferecer serviços e mercadorias. Segundo a antropóloga Juliana Blasi Cunha, nas décadas de 1960 e 1970, há um crescimento exponencial do turismo na região e centenas de casas para veraneio são construídas, principalmente por famílias campistas, na região próxima a orla:

(...) residências de vilegiatura alastram-se consideravelmente marcando presença nas ruas do balneário (...) grande parte dos terrenos foram 'cedidos' pela Marinha, bastando fazer a solicitação na Capitania dos Portos, em São João da Barra. ${ }^{5}$

É neste mesmo período que se intensifica o processo de erosão costeira no território. A erosão atingiu inicialmente as ilhas da Convivência e do Peçanha, local onde viviam mais de 300 famílias de ribeirinhos, que foram obrigadas a

\footnotetext{
4 Foram os pescadores os primeiros colonos a conseguirem se fixar na região. Após as tentativas fracassadas dos primeiros donatários Pero de Góis e Gil de Góes, foi o pescador Lourenço do Espirito Santo em 1622 quem conseguiu se fixar no território que mais tarde vai se tornar o Município de São João da Barra. Sobre o assunto, ver o livro A Terra Goytacá: à luz de documentos inéditos, de Alberto Lamego Filho.
}

5 Cunha, 2007: 78. 
migrar para Atafona. Esta migração transformou violentamente o modo de vida destes moradores, ocasionando na perda de muitas de suas práticas culturais tradicionais. A erosão destruiu também toda a vasta região conhecida como o "Pontal de Atafona", que continha um enorme manguezal, uma pequena lagoa e uma longa faixa de areia, área preferida pelos turistas e onde se concentravam a maior parte dos bares e restaurantes. Até o momento, o mar já engoliu mais de 15 ruas e 500 construções entre casas de pescadores e veranistas, clubes, igrejas, postos de gasolina, bares e até um prédio ${ }^{6}$. Toda esta destruição teve um efeito desastroso para a economia local e afastou a maior parte dos turistas, que hoje têm privilegiado outras praias da região como destino para os períodos de descanso.

Compreendemos que o drama socioambiental de Atafona não é um caso isolado no Brasil, mas faz parte de um projeto desenvolvimentista extrativista mais amplo, "um mundo em que o mundo vai engolindo o mundo, movido pela geoeconomia e pela tecnociência"7. O processo erosivo atual na foz está diretamente ligado às inúmeras intervenções humanas no leito do Rio Paraíba do Sul, a principal delas a transposição de $2 / 3$ do volume de água do Paraíba para o Rio Guandu com o objetivo de fornecer água para região metropolitana do Rio de Janeiro ${ }^{8}$. Em nosso entendimento, a erosão em Atafona é mais uma das consequências de um modelo criminoso e irresponsável de exploração dos recursos naturais, modelo que tem produzido sequenciais crimes socioambientais, como nos casos das cidades de Brumadinho e Mariana.

Como diz Eloisa Brantes, a partir da experiência de residência de arte Foz Afora com o coletivo Líquida Ação, ação desenvolvida durante 22 dias na foz do Rio Doce em Vila de Regência (ES) um ano e meio após o rompimento da barragem de rejeitos de mineração do Fundão pertencente à Mineradora Samarco S.A:

Cidades, regiões e povoações em recorrente estado de crise hídrica aumentam a passos largos no Brasil. Resposta da natureza violentada pela economia predatória que,

6 Trata-se do "prédio do Julinho". Segundo o jornalista Arnaldo Neto, o edifício foi construído em 1970 por Júlio Ferreira da Silva. O prédio, que seria um hotel, tinha quatro pavimentos e abrigaria 48 suítes. As obras não chegaram a ser terminadas e o hotel nunca funcionou, mas no térreo chegaram a funcionar vários comércios (Neto, 2018).

7 Wisnik, 2018:19.

8 Sobre o assunto ver Oliveira (2015) e Barbosa (2020). 
desde a colonização branca até os atuais projetos neodesenvolvimentistas de fomento a mineração e ao agronegócio, é mantida em nome da ordem e do progresso. A destruição dos rios legitimada pelo crescimento econômico se tornou uma espécie de fatalidade social, como se fosse inevitável a transformação dos rios em esgotos ${ }^{9}$.

O modelo de desenvolvimento do município de São João da Barra (RJ) é representado pelo Complexo Logístico e Industrial do Porto do Açu (CLIPA), um dos maiores complexos portuários da América Latina, construído, entre outras coisas, para receber um gigantesco mineroduto que atravessa 32 munícipios a partir do município de Conceição do Mato Dentro (MG). A implementação do complexo foi marcada por inúmeras violações dos direitos humanos, com a expropriação violenta de aproximadamente 1.500 famílias e diversos impactos ambientais graves, tais como a salinização do solo da região, processos erosivos na costa, impactos em áreas de pesca e poluição de lagoas. Segundo Noêmia Magalhães, liderança local que resistiu ao processo de desapropriação, o empreendimento é um verdadeiro algoz da comunidade:

A descoberta da verdadeira realidade, descobrir que este projeto ia alterar o modo de vida de gerações de mais de cento e cinquenta anos, pescadores e pequenos agricultores familiares, que escreveram a história do município de São João da Barra. Transformaram propriedades legalizadas em réus ignorados, transformaram as pessoas dignas e simples em números, porcentagens, fazendo com que em sua humildade e ignorância não entendessem o perigo e muitos fraquejassem, deprimissem e até morressem de desgosto, pois, em sua inocência e humildade, custaram a entender que quem estava ali não era o progresso amigo e um futuro melhor, mas um algoz sem face...10

O caso do Porto do Açu demandaria um artigo à parte, importa aqui ressaltar que este megaempreendimento faz parte do mesmo modelo de desenvolvimento que vem agredindo ecossistemas brasileiros, e que é mais um empreendimento que atinge diretamente a comunidade de pescadores de Atafona.

Assim, se no plano da política interna brasileira, o caso de Atafona nos alerta para uma necessária revisão no nosso modelo de gestão dos recursos naturais e em especial dos recursos hídrico. No plano da política externa, Atafona é um chamado para a tomada de consciência face às consequên- 
cias brutais do acelerado processo de aquecimento global em curso, decorrente das emissões de gases de efeito estufa. A ambientalista e pesquisador sobre a região, Aristides Soffiati, indica um estudo realizado pelo instituto Climate Central ${ }^{11}$, no qual podemos observar que se a temperatura média do planeta aumentar 2 graus célsius, o mar chegará perto da Lagoa de Cima12; se aumentar 4, a lagoa será afogada e o mar chegará ao pé da serra. Ou seja, se estas previsões estiverem certas, com o aumento da temperatura do planeta, não só Atafona vai desaparecer, mas toda a planície Goytacá, ou seja, todo o munícipio de São João da Barra, grande parte dos municípios de Campos dos Goytacazes e São Francisco de Itabapoana e ainda parte de Quissamã, isto para nos determos sobre a região Norte-fluminense

Neste contexto, trazemos o conceito de Antropoceno como um norteador deste campo de estudos. Este conceito se refere, segundo os estudos atuais sobre as mudanças climáticas, à denominação de uma era geológica que teria se iniciado com a Revolução Industrial e se intensificado após a Segunda Grande Guerra, na qual os efeitos de nossas ações enquanto espécie causam transformações irreversíveis ao equilíbrio energético do planeta Terra. Entendemos que este "evento Antropoceno" é resultado de uma série de escolhas políticas, econômicas e tecnológicas que constroem ativamente essas mudanças que ele designa, e que sempre houveram informações a respeito do prejuízo de ciclos bioquímicos que tais perturbações poderiam produzir. ${ }^{13}$

Como compreender a decisão política de desviar um rio a ponto de depauperá-lo? Como as pessoas diretamente afetadas pela erosão, que perdem sistematicamente suas construções, convivem com esta realidade? 0 que tais decisões políticas e os silenciamentos que ocorrem nestes quadros dizem sobre o funcionamento de uma sociedade? No sentido destas questões, a destruição do território de Atafona se apresenta como uma metáfora viva da destruição provocada por um modelo civilizatório, compreendido aqui em uma perspectiva geopolítica da história do Brasil. Ve-

11 Trata-se da ferramenta Mapping Choices. Disponível em: https://sealevel.climatecentral.org/. Acesso em: 05 fev. 2020.

12 Importante ponto turístico da cidade de Campos dos Goytacazes a lagoa está localizada a $28 \mathrm{~km}$ do centro urbano do município em sentido oposto ao mar.

13 Para informações bem detalhadas sobre isto, ver o livro: L'Éve】nement Anthropoce】ne (Bonneuil; Fressoz, 2013). 
Figura 1 Vista das ruínas do prédio do Julinhno praia de Atafona. Foto: Fernando Codeço, 2017

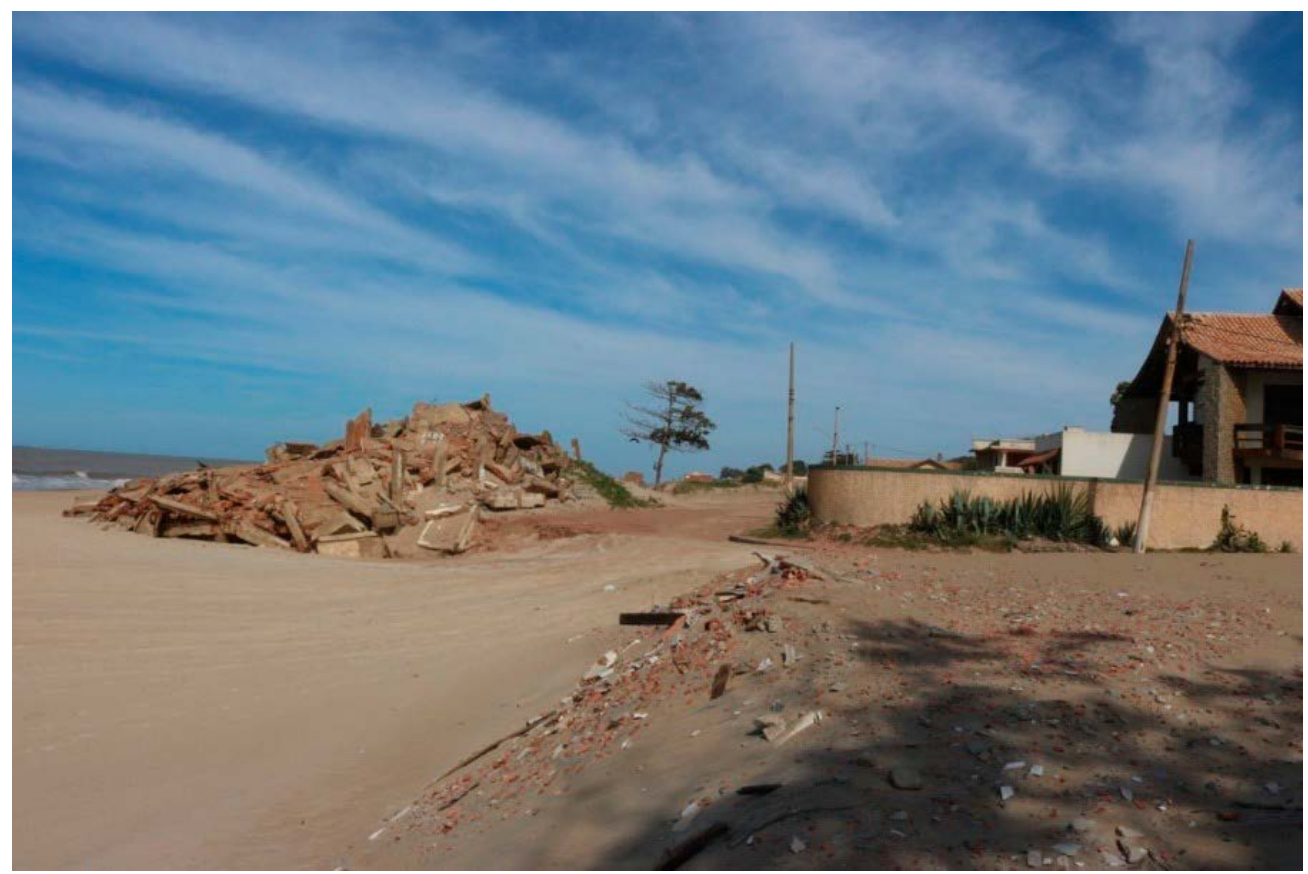

mos o modus operandi colonial do capitalismo brasileiro atuando de forma nítida, levando comunidades à destruição em nome de um modelo de "desenvolvimento", o que o filósofo camaronês Achille Mbembe chama de necropolítica. Isto é, a partir de decisões políticas, determinados territórios (culturas, populações) devem ser destruídos para que outros se desenvolvam. Seguindo Mbembe, "história, geografia, cartografia e arqueologia supostamente apoiam essas reivindicações, relacionando estreitamente identidade e topografia" (Mbembe, 2018: 42).

Hoje, Atafona possui a aura de glamour decadente misturado a uma vida simples, pesqueira e provinciana. Apresenta a imagem de um resto de um tempo perdido de uma história abafada: o desmoronamento de uma praia e a destruição de modos de vida tradicionais em uma ponta do Brasil, sequenciais colapsos administrativos, abandono generalizado, infraestrutura vulnerável e a ausência quase total de políticas públicas destinadas às pessoas diretamente afetadas pela erosão.

Uma vida em meio a escombros, restos e deslocamentos; pessoas nascem e erguem casas em terras em franco processo erosivo. Um empobrecido mangue entre as pequenas ilhas, famílias resistentes no meio da contínua destruição de seu espaço, onde se come peixes, ovas, caranguejos em abundância, frutas e mandioca. Onde os pescadores encontram cada dia maiores dificuldades para navegar no rio e cada vez menos peixes, os pequenos comerciantes vivem no limite, trabalhadores em situação de pre- 
carização, mães jovens, todos órfãos de um imaginário pai-patrão. O mar todo dia ruindo a terra pouco-a-pouco, e levando junto um mundo humano erigido sobre ela.

Para se ter uma dimensão da área destruída pela erosão até aqui, apresentamos um mapa ${ }^{14}$ criado por um grupo de pesquisadores sob coordenação do cartógrafo Gilberto Pessanha Ribeiro ilustrando as mudanças no desenho da costa de Atafona entre 1954 até 2000.

Figura 2

Mapa do litoral de Atafona. Fonte: Texto Processos Costeiros: Erosão em Atafona e progradação em Grussaí, São João da Barra (RJ) Morfometria Para Retratação Espacial Desses Eventos e Identificação de Sua Tendência Evolutiva, Gilberto Pessanha, 2006.
DINAMICA DO LITORAL EM ATAFONA Sistema de coordenadas UTM. Sistema geodésico SAD - 69.

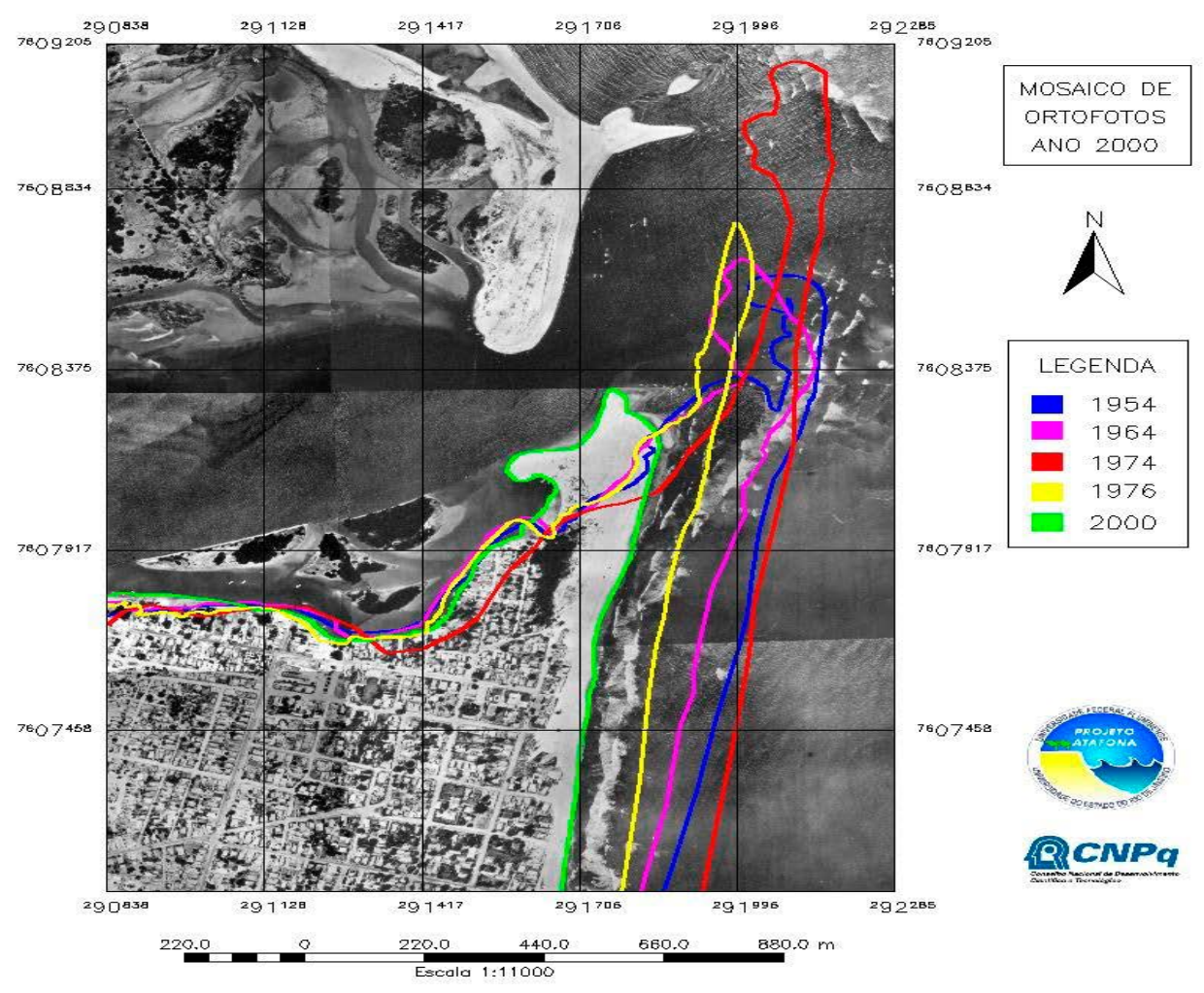

Na imagem seguinte, vista aérea do Pontal no ano de 1974, traçamos uma linha vermelha para indicar aproximadamente aonde o mar se encontra hoje, em 2020. 
Figura 3

Imagem aérea 1. Fonte: Autor desconhecido, parte do acervo fotográfico que adquirimos do artesão Jair Viera

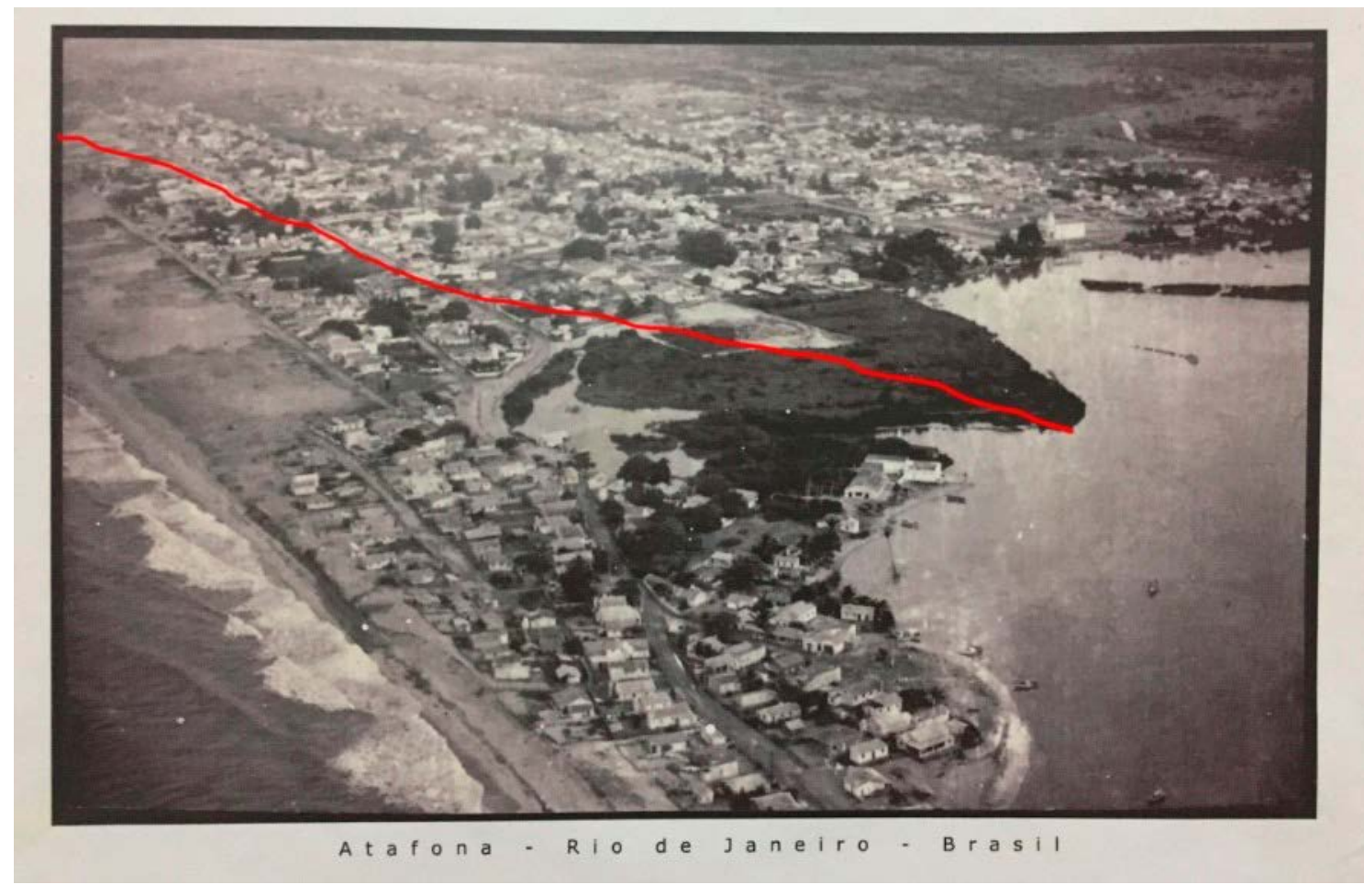

A intervenção proposta foi a de posicionar a CasaDuna nesse ambiente como um projeto de pesquisa e de produção de cultura, arte e memória que não simplesmente reproduza as lógicas e violências internas aos procedimentos históricos, mas também não negue sua concretude, seus efeitos sobre os homens, as terras, as águas e os mangues. Reconhecer a irreversibilidade de certas mutações não significa aceitar as políticas que pretensamente decorrem dessas mutações, mas que, em realidade, são ditadas pela visão de mundo dos interesses dominantes. Reconhecê-las, ao contrário, nos faz procurar saídas a partir de novos modos de agir e novas inteligências políticas e sociais, com procedimentos distintos dos atuais.

\section{Segundo afirmam Danowski e Viveiros de Castro,}

A bela estratificação sociocosmológica da modernidade começa a implodir diante de nossos olhos. Imaginava-se que o edifício podia se apoiar apenas sobre seu andar térreo, a economia, mais eis que nos esquecemos das fundações ${ }^{15}$.

Assim, CasaDuna surge como um gesto ativo neste cenário, um movimen- 
to de produzir discursos e narrativas contextuais e inserir este pedaço de costa brasileira na história em um campo estético e político, contribuindo com a ampliação da percepção e do discurso sobre esta situação. Com este gesto, trabalhamos especificamente a questão do território, compreendido como um ecossistema físico e semântico no qual nossa prática se estabelece. Enquanto pesquisadores, artistas e produtores de arte contemporânea, algumas questões se colocam: quais são as relações, estéticas e políticas, entre as formas de expressão e o contexto no qual elas se realizam? Esta pergunta é colocada através de uma problematização do próprio lugar da arte em um mundo em ruínas.

\section{A arte contextual como instrumento metodológico}

Como lembra Giorgio Agambem, "toda cultura é antes de mais nada uma certa experiência do tempo, e não existe cultura nova sem transformação dessa experiência"16. Segundo o historiador de arte Paul Ardenne no livro Un art contextuel - Création artistique en milieu urbain, en situation, $d^{\prime}$ 'intervention, de participation ${ }^{17}$, o papel do agente cultural pode ser o de estabelecer pontes de conexão com outros artistas e disciplinas, mas também o de criar ações que conectem os próprios indivíduos atuantes em um campo. Isto é, criar novas relações sociais. A arte contextual é uma intervenção em uma relação com uma realidade concreta. Além disso, ela se distancia das formas tradicionais do mundo da arte como as de representação, apropriação, ou mesmo a arte conceitual, que questiona a si mesma. O que chamamos aqui de arte contextual se dedica a buscar um potencial crítico e estético de práticas artísticas no campo da apresentação/proposição de ações, e não tanto na criação de representações. Assim, este é um tipo de prática artística que se afasta também dos suportes tradicionais das artes como quadro, escultura, objetos. Esses suportes podem até também ser criados, mas isso se dá a partir de uma produção posterior, ou complementar, como um desdobramento.

A partir da década de 1960, no campo das artes, viu-se um movimento forte em direção a um novo tipo de relação entre a arte e o mundo. Muitos 
nomes foram dados: arte de intervenção, arte engajada, arte ativista, art in situ, arte ambiental... Tais nomes se referem normalmente a criações coletivas que podem fazer uso de práticas artísticas (ou não) em contextos não artísticos, expostas às vicissitudes do mundo material no cotidiano das ruas, feiras, praças.

Segundo Ardenne, o contexto "designa o conjunto de circunstâncias que são em situação de interação (o "contexto", etimologicamente, é uma "montagem" da base latina contextus de contextere, tecer com)"18. Isto demonstra que não estamos no terreno do idealismo ou da representação e sim na tentativa de infiltração no cotidiano das ordens das coisas, dos acontecimentos possíveis. A partir de uma relação com o mundo, tal qual ele se apresenta, busca-se criar condições para praticas artísticas que rompam ou questionem um habitual. Assim, constrói-se um trabalho de pesquisa local que tem a escuta e a adaptação como orientação fundamental: "vigie os fatos, escute os barulhos". ${ }^{19}$

No caso que apresentamos aqui, vivemos uma prática que radicaliza as noções de campo e de pesquisa, desestabilizando-as ao definir o campo de intervenção pela sua metaestabilidade, sempre ligado a condições exógenas e instáveis, e a pesquisa, por erodir as posições e oposições que ela cria, sejam elas entre sujeito e objeto, entre local e global, entre o eu e o outro, indivíduo e grupo, etc. A pesquisa é, então, o trabalho prático em uma situação específica para dar expressão a processos de produção diferenciados no campo da cultura e também da produção científica. As implicações e efeitos que resultam dessas intervenções permitem acessar, nas instituições, os processos políticos e os respectivos obstáculos, epistêmicos e funcionais, em suas lógicas internas. A direção desse método visa acessar o que se passa entre os estados ou formas instituídas, tantas vezes atrofiadas a um ideário de Modernidade insuficiente e desconectado com a realidade vivida em territórios levados à precariedade. O crítico e historiador de arte norte-americano Hal Foster em seu livro $O$ retorno do real ${ }^{20}$ discorre sobre os principais movimentos da arte contemporânea e salienta as relações de retroimplicações entre arte e política desde a década de 1920 até os dias atuais.

18 Ibidem: 17.

19 Ibidem: 20.

20 Foster, 2014. 
A arte pós-modernista é alegórica não só por sua ênfase nos espaços em ruínas (como nas instalações efêmeras) e nas imagens fragmentárias (como em apropriações da história da arte e dos meios de comunicação de massa), mas, acima de tudo, por seu impulso para subverter as normas estilísticas, para redefinir as categorias conceituais, para desafiar o ideal modernista de totalidade simbólica 21.

Uma das apostas da CasaDuna é a circulação de pessoas e ideias dentro e fora de espaços institucionalizados e dos principais centros urbanos. Isto é, produzir uma circulação entre práticas e saberes acadêmicos e populares, urbanos e rurais. Esses deslocamentos ativam uma escuta mais ampla dos problemas referentes aos nossos pressupostos metodológicos e epistemológicos e as necessárias traduções, adaptações e transformações que devem se efetivar para criar ações contextuais.

\begin{abstract}
Favorecemos as intervenções que exploram ativamente as relações atuais relativas a: inter/trans/não-disciplinar; a emergência de novos modos de colaboração; a micropolítica e a vida (e a morte) das instituições; a criatividade, a subjetividade e a coletividade da produção cultural; a ética da estética; a estética como ética. Visamos a promoção de práticas experimentais que combinam a pesquisa e a criação no intuito de forjar conexões simbólicas entre a enquete filosófica, a inovação tecnológica, a produção artística e o engajamento político e social.22
\end{abstract}

Quando começamos os trabalhos da residência de arte e de produções de exposições em São João da Barra e em Atafona, percebemos que nosso trabalho não se restringiria a questões de curadoria e montagem, como seleção de artistas, obras e conceitos expográficos; tampouco nos limitávamos a focar na relação entre as obras e a exposição. Era necessário um trabalho anterior que envolvia uma ação de articulação de redes, de formação de público e de produção conceitual e logística territorial, inclusive econômica, que viabilizasse cada ação proposta. Isso nos fazia refletir e intervir também sobre o próprio modo de produção. Como bem diz, Pál Pelbart,

nada está dado, nada está garantido, tudo pode colapsar, a obra, o criador, a instauração, mas essa hesitação é o próprio processo, não insuficiência ontológica nem falha constitutiva. É que o trajeto vital é feito de exploração, descobertas, encontros, cisões, aceitações dolorosas23.

21 Ibidem: 92.

22 Giacco, 2018: 87.

23 Pál Pelbart, 2016: 394. 
Nos engajamos na produção de uma proliferação discursiva, seja ela um metadiscurso sobre a destruição evidente, seja um deslocamento do que vulgarmente entendemos por destruição (como, por exemplo, quando tiramos a destruição do campo geofísico e a transportamos para corpos cênicos), seja quando fazemos um teatro cujos pilares do que se entende por teatro clássico estão erodidos (como personagens, narrativa, interpretação, etc.), seja ela um agenciamento imprevisto e incompreensível à discursividade habitual local.

\section{Relatos de experiências}

O nome CasaDuna é literal - ele faz referência a uma casa invadida por uma duna. Quando chegamos em Atafona em 2017, procuramos por uma casa com espaço suficiente para funcionar como sede de nosso coletivo de arte, com espaço para ateliê, hospedagem para artistas residentes, e que nos possibilitasse também produzir eventos culturais de diferentes naturezas. Uma "casa grande". Já havia neste momento uma preocupação com esse símbolo. Sabíamos que chegávamos para trabalhar num contexto herdeiro de um profundo coronelismo e não podíamos ignorar as marcas históricas que tais símbolos produzem. Neste sentido, o encontro com a residência que decidimos alugar foi impactante. A casa pertencia a uma conhecida família campista, herdeiros da usina de açúcar Cambahyba. Com a falência da usina, a família havia perdido o poderio econômico e político de outrora. No entanto, a fama permanecia no imaginário da população. Sabíamos que por este motivo o uso daquela casa poderia ampliar a visibilidade de nossas ações culturais nos veículos de comunicação locais, o que acabou por se mostrar real. Mas o elemento determinante na nossa decisão pelo imóvel era o fato de que pouco tempo antes de nossa chegada, uma grande duna havia invadido o terreno, derrubando o enorme muro que protegia a casa dos olhares dos passantes curiosos.

A formação de dunas é um fenômeno decorrente da erosão costeira, e seu avanço é também um dos fatores ambientais que ameaçam destruir as residências localizadas na orla de Atafona. Algumas casas, inclusive, já chegaram a ser soterradas. Como o avanço das dunas é lento e o espaço que a separava da casa era ainda grande o suficiente para não apresentar riscos para os próximos anos, decidimos então que este era o lugar perfeito, pois, além de suprir as nossas necessidades em termos de espaço e infraestrutura, a casa continha uma forte carga simbólica. A transgressão dos limites daquela propriedade pela duna possibilitou que transfigurássemos 
Figuras 4 a 7 Vistas da CasaDuna.Fotos: Fernando Codeço, 2017

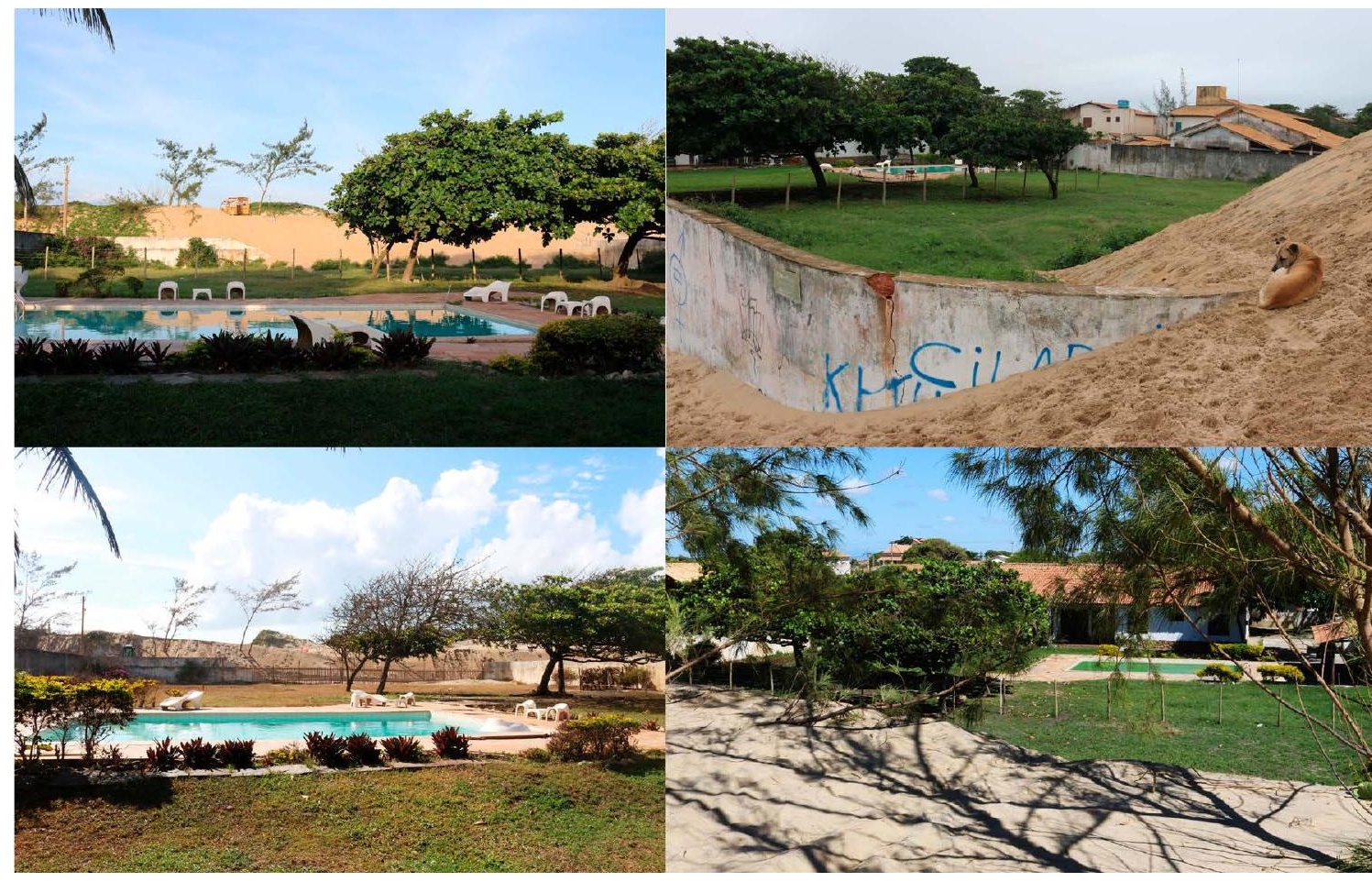

o uso daquele espaço, antes reservado ao luxo privado de uma poderosa família de usineiros campistas, em um espaço cultural aberto ao público, com rica programação de cinema, teatro e artes visuais. Compreendíamos assim a própria ocupação daquela casa, que passamos a chamar de CasaDuna, como um gesto estético, performativo e conceitual.

A imagem da duna invadindo esta mansão possui uma significação histórica que merece ser comentada. A casa foi construída na década de 1970, em plena ditadura militar, com a riqueza oriunda de espúrias relações com o governo federal. De acordo com o depoimento do ex-delegado Cláudio Guerra obtido pela Comissão Nacional da Verdade, corpos de presos políticos foram queimados nos fornos de uma das usinas da família:

Guerra disse que levava os corpos para a usina Cambahyba, em Campos dos Goytacazes (RJ), que pertencia a Hely Ribeiro Gomes, ex-vice-governador do Rio de Janeiro. Segundo Guerra, esses corpos eram oriundos da Casa da Morte, em Petrópolis, e do quartel da Polícia do Exército (PE) na rua Barão de Mesquita, no Rio de Janeiro (Relatório da Comissão da Verdade, Vol. 1, 2014, 521).24

24 Este caso foi narrado em dois filmes, "Pastor Claudio" (Beth Formaggini, 2018) e "Forró em Cambaíba" (Victor Menezes, 2014). Há controvérsias sobre o caso. A filha do dono da usina nega as alegações de Claudio Guerra. No entanto, seu depoimento é 
A casa, que pertencia ao filho de Hely Ribeiro, local de veraneio e descanso desta "tradicional família brasileira", pode muito bem ter sido palco também de "tenebrosas transações". Se nos remetemos a este fato histórico, não é para imaginarmos uma possível "justiça divina" sendo feita por nós, mesmo porque sabemos que a erosão atinge indiferentemente a ricos e pobres, e, se fosse caso, o "castigo" teria chegado tarde demais. O que nos interessa pensar é a ideia da erosão desta arquitetura, que guarda na sua própria forma uma estrutura que se fixa no imaginário popular como expressão de um poder opressivo e violento.

Assim, a tarefa de ressignificar este espaço enquanto local de encontros para fruição e produção de arte crítica e libertária possuía uma dobra política que remetia a fatos importantes e traumáticos da história recente do país. Mais tarde, percebemos que a carga simbólica desta casa nos colocava limitações difíceis de superar. No entanto, durante um ano que passamos lá, pudemos produzir um número significativo de eventos, contribuindo com o cenário cultural e intelectual da região. ${ }^{25}$

Para falar mais diretamente para a comunidade sobre o que éramos e o que propúnhamos, usamos em nossa primeira exposição o conceito de "museu". Utilizamos o salão principal da casa como galeria, construímos varas com treliças de laje para criar uma iluminação apropriada. Com esta estrutura, expusemos parte do acervo que havíamos adquirido recentemente, um conjunto significativo de imagens históricas da área atingida pela erosão, imagens de um território hoje submerso. Conseguimos, através de uma chamada pela internet, reunir um número expressivo de artistas que haviam produzido trabalhos sobre Atafona, principalmente através da fotografia. Expusemos também os trabalhos das primeiras artistas residentes que recebemos na casa, Mariana Moraes e Renata Lamenza. Tivemos ainda a generosa contribuição do historiador e guia turístico André Pinto, profundo conhecedor da região e figura influente no meio cultural local, que, além de nos ajudar na curadoria, apresentou registros de sua pesquisa sobre os "muxuangos", nome utilizado por historiadores para se referir à população ribeirinha da ilha da Convivência.

detalhado e fortemente verossímil.

25 Estão disponíveis no site da CasaDuna os registros fotográficos das ações educativas e culturais realizadas durante este período. 
Chamamos esta primeira exposição de Atafona: museu em processo. Utilizamos esse nome como uma forma de provocação, uma tentativa de despertar a necessidade da produção de um museu de Atafona, mas sabíamos que não poderíamos construir tal museu sozinhos. A exposição funcionava como um chamado, uma ideia que poderíamos experimentar em formato embrionário, para, quem sabe a partir de outras iniciativas, vir a construir um museu comunitário. Seguimos ainda hoje com o desejo de refletir sobre outros formatos de museu na atualidade que sejam mais afinados com realidades complexas nas comunidades contemporâneas. Acreditamos que iniciativas como as do Museu das Remoções ${ }^{26}$ e o Museu da Maré27, no Rio de Janeiro, podem servir de referência para a construção de um museu em Atafona, por serem experiências de museu que, para além de um cubo branco com cânones da "cultura" e do "valor", se infiltram na vida cotidiana e trabalham com a produção de memória (e de relação com trauma) para uma transformação de sentidos em uma situação local.

Além da exposição, fizemos diversos eventos na casa, cineclube com seleção de filmes brasileiros, cabarés, apresentações teatrais, palestras, além de festas e shows musicais. Acreditávamos que, com a produção de festas e shows, no verão conseguiríamos recursos para continuar financiando as atividades culturais que oferecíamos gratuitamente. No entanto, encontramos barreiras políticas e institucionais que inviabilizaram tal projeto. Uma intricada e onerosa trama burocrática para aquisição de alvarás, aliada a um jogo político provinciano e protecionista, impediram que pudéssemos cobrar entrada para nossos eventos. Mesmo com essas dificuldades, realizamos os eventos que havíamos programado para o verão de 2018. No entanto, a continuidade deste modelo de projeto se mostrou inviável economicamente, o que nos fez repensar nossas estratégias de ação no território. A carga simbólica da casa como espaço privilegiado da elite campista afastava o povo mais simples da localidade, frustrando um de nossos objetivos iniciais, o de dialogar com a comunidade nativa.

Antes de falarmos desta reestruturação do projeto, cabe destacar uma de nossas ações que se deu nos últimos meses em que habitamos aquela casa. Trata-se da apresentação do happening $O$ muro, primeiro trabalho realizado pelo Grupo Erosão, coletivo de teatro que fundamos junto com 
as atrizes Lucia Talabi e Jailza Mota. ${ }^{28}$ Esse happening surgiu sobre a necessidade de trazermos o debate sobre o polêmico projeto de contenção do mar apresentado pelo INPH, o que envolveria a construção de nove espigões de concreto. Este é um projeto complexo e custoso, que divide comunidade, cientistas e políticos quanto a seus impactos, viabilidade e eficácia. Sabemos que tais projetos têm sido recorrentemente utilizados para alimentar a esperança da população num jogo que, no fundo, não passa de estratégias políticas eleitoreiras. O elevado custo da obra, a falta de consenso científico e sobretudo a falta de interesse estratégico na região a nível nacional tornam esta construção muito pouco provável. No entanto, o assunto não saí de pauta entre os moradores de Atafona.

$O$ muro $^{29}$ foi a forma que encontramos para nos inserirmos neste debate através de uma linguagem situada entre o teatro e as artes visuais. A ação agregava no seu próprio processo um trabalho de arte-educação realizado com crianças de um grupo de escoteiros local. Interessa-nos destacar nesta ação o seu potencial de diálogo e dissenso, uma ação que gerou estranhamentos em diferentes sentidos. Tal ação consistia na construção e derrubada de um muro feito inteiramente com materiais coletados das ruínas das casas destruídas pela erosão, no meio do gramado da casa.

Todo o processo levou três dias para ser realizado. No primeiro dia, coletamos com ajuda de um carroceiro uma grande quantidade de escombros, ação que nos demandou grande esforço coletivo e nos colocou em relação com a figura do carroceiro, tipo social cuja presença denota a sobrevivência de práticas camponesas nesta praia já bastante urbanizada. Resolvemos então utilizar a própria carroça como elemento cênico para a nossa performance. Esse elemento nos interessou, pois reforçava a dimensão "primitivista" e antidesenvolvimentista do trabalho.

No segundo dia, realizamos o trabalho educativo com o grupo de escoteiros. ${ }^{30}$ Convidamos as crianças a construir o muro conosco. Neste processo discutimos com elas as diferentes significações desta ação por meio de diferentes jogos. Propusemos questões tais como: para que serve um muro?

28 A lista completa dos integrantes do grupo atualmente se encontra no já referido site da CasaDuna.

29 Ver registros da performance no link: https://www.casaduna.org/duna-em-cena.

30 Registros da ação estão disponíveis em: https://www.casaduna.org/educativo-casaduna. 
Seria possível um mundo sem muros? Muros são realmente necessários? A ação se mostrou bastante envolvente e criou fricções com a estrutura pedagógica e disciplinar específica dos grupos de escoteiros, oportunizando a experimentação de outras formas relacionais e reflexões conceituais.

Por fim, no terceiro dia, realizamos o evento propriamente do happening, ação cênica previamente ensaiada que incluía, entre outras ações, a derrubada do muro. Este evento criou uma nova camada de estranhamento, pois o realizamos em parceria com uma associação local de artesãos em uma feira de artesanato, contexto de um público não especializado em arte contemporânea. Ajudamos a produzir um bazar de verão em nossa casa e, no dia do evento, O Muro estava ali, construído no meio do nosso jardim. Aquele muro feito de escombros, vergalhões e ruínas era "feio", "esquisito", para os padrões da maioria dos artesãos e do público atraído por eles. Desde o início do evento, começamos a perceber comentários e burburinhos mal disfarçados sobre a linguagem que estávamos propondo. Criamos assim, uma espécie de infiltração, um estranhamento, uma ação inesperada para o público daquele bazar, causando dissensos, ruídos e descontinuidades discursivas. Uma reflexão sobre complexidade da interferência humana nas mudanças climáticas é algo que alarma a população diariamente, e ainda assim é um tema espinhoso, que gera muita resistência em grande parte da comunidade. Realizamos esta reflexão por meio da linguagem da arte contemporânea em locais onde essa linguagem não existe e acreditamos que essa atitude tem grande potência.

Conseguimos muita visibilidade, muitas realizações e importantes parcerias locais enquanto ocupamos aquela mansão de veraneio, mas as referidas implicações econômicas e simbólicas intrínsecas àquele espaço nos levaram a reformular nosso projeto. Sentimos a necessidade de mudar o foco de nosso trabalho, que até então vinha sendo feito principalmente no interior daquela casa e, ainda que os eventos fossem públicos, eles estavam ocorrendo em um espaço privado. Percebemos que só conseguiríamos atingir o público local de Atafona e São João da Barra se fizéssemos eventos na rua ou nos equipamentos culturais da prefeitura, pois a comunidade local dificilmente entraria naquela "casa grande" para assistir a um evento de teatro ou artes plásticas de um coletivo recém-chegado na região. Diante disso, resolvemos nos mudar para uma casa menor e menos onerosa, e começamos a desenvolver projetos para serem realizados na rua ou em espaços da prefeitura. Neste mesmo período, após o primeiro ano de trabalho, o projeto da CasaDuna passa a integrar o Programa de Pós-doutorado em Políticas Sociais na Universidade Estadual Norte-Fluminense (UENF), em Campos dos Goytacazes. 
Sabíamos desde o início do enorme desafio de nosso projeto, principalmente no tocante à viabilização financeira e à adesão por parte da comunidade local. Toda ação que fosse proposta deveria ser definida em função das próprias condições de fragilidade e de resistência sócioterritorial. Um de nossos objetivos era o de criar uma articulação entre pesquisa e produção acadêmica ${ }^{31}$, por um lado, e ações em arte contemporânea, por outro, como um "gesto agente" que visava efetuar uma torção no modo como tradicionalmente elas são operadas, tanto no campo dos investimentos em produção cultural, quanto no investimento em pesquisa acadêmica - prioritariamente quantitativos e destinados a conjunturas em "desenvolvimento".

Neste sentido, criar uma rede de colaboração local e o apoio institucional das universidades públicas, além de um desejo, seria um elemento fortalecedor, uma vez que as universidades desenvolvem projetos de pesquisa na região. ${ }^{32}$ Assim, a atitude de inserir a CasaDuna na universidade pode ser compreendida como uma estratégia de resistência para a viabilização do trabalho, mas também como um ativismo dentro da própria instituição pela urgência de revisões epistemológicas, ampliando o espaço no campo do conhecimento legitimado para saberes menores, modos de vida menores, vidas outras.

Com esta entrada, demos início ao que hoje se tornou o Projeto de Extensão TEIA, fundado com o objetivo de estabelecer redes colaborativas de diferentes instituições de ensino na cidade de Campos (UENF, IFF e UFF), e que foi fundamental para a viabilização do projeto Erosões Visuais, que realizamos em parceria com o curador cubano Andrés Hernandes no final de 2018. O projeto consistiu em uma residência de arte com 9 artistas de diferentes estados do país, uma exposição em Campos na Casa de Cultura Villa Maria e outra em São João da Barra na antiga Casa de Câmara e Cadeia, e a apresentação do espetáculo de rua Tempontal, do Grupo Erosão ${ }^{33}$.

31 Programa de Pós-Doutorado em Políticas Sociais da Universidade Estadual Norte Fluminense (PPGPS-UENF) e Programa de Pós-graduação em Artes da Cena da Universidade Federal do Estado do Rio de Janeiro (PPGAC-UNIRIO).

32 A UENF, ao longo de seus 20 anos de existência, atua de forma significativa com a comunidade local através de projetos de extensão que conseguem alguma penetração com a comunidade.

33 Hoje, este Projeto de Extensão conta com 20 bolsistas de graduação que participam de todas as etapas do processo de montagem da exposição e trabalho com museologia na cidade de Campos dos Goytacazes. 
Para a realização da residência, desejávamos compor um grupo heterogêneo de artistas, mas que incluísse a participação de artistas da região norte-fluminense. Isto não era tarefa fácil, visto a quase inexistência de artistas familiarizados com a linguagem da arte contemporânea na região. Até os últimos dias da pré-produção, contávamos com 2 artistas locais e achávamos que seriam os únicos, até termos um encontro muito especial. No processo de busca de apoio/patrocínio dos comércios locais, fomos a fábrica de bebidas Toquino, importante indústria da cidade. ${ }^{34}$ Começamos a conversar com o funcionário chamado Anjo Amauri e quando começamos a falar do nosso projeto, ele nos disse que já tinha ouvido falar de nosso trabalho através de uma matéria de jornal. Ele nos falou de sua paixão por Atafona, e que há alguns anos desenvolvia uma série de autorretratos, nos quais seu corpo não normativo, sempre em relação com a paisagem local, punha em xeque tabus referentes a gênero, religião, natureza, liberdade e violência. Ao vermos suas fotos, percebemos uma afinidade profunda com a proposta de arte contextual que vínhamos desenvolvendo. O trabalho de Amauri é um exemplo de como a arte pode ultrapassar muros e formas predeterminadas de modos de produção, dizendo respeito, antes, a modos de expressão que reconfiguram subjetividades e organizações semânticas. Esse encontro nos fez reorganizar o material e o grupo que considerávamos fechado. Mesmo a proposta da residência foi alterada, pois ela previa uma imersão do/as artistas em nossa casa durante 10 dias, tempo que, naturalmente, Amauri não dispunha, pois trabalhava na fábrica e não tinha o modo de vida de artistas que comumente possuem uma organização mais flexível de seu tempo.

Desta forma, a relação com Anjo Amauri foi diferente. Primeiro, pois era necessário que nos adaptássemos às suas possibilidades para a produção de uma série fotográfica especifica para o nosso projeto. Além disso, a imersão local que propúnhamos para o/as artistas, não era imprescindível para Amauri, uma vez que ele já mora em São João da Barra. Amauri, através desse projeto, teve pela primeira vez seus trabalhos impressos e expostos em um centro cultural, na Casa de Cultura Villa Maria, em Campos, espaço que ele próprio foi visitar pela primeira vez por ocasião desta exposição. Além disto, a participação dele no conjunto dos trabalhos chamou muita atenção, pois a apresentação do território que vemos através das imagens

34 Inclusive, uma das maiores empresas de bebida de capital nacional, criadora do famoso Conhaque de Alcatrão. 
produzidas por ele tem uma singularidade muito importante em relevar a beleza e a potência dos corpos que forjam as formas habituais - tanto as de seu corpo como as de Atafona.

Figuras 8 a 11 Fotoperformance de Anjo Amauri na praia de Atafona. Fotos: Anjo Amauri, 2016

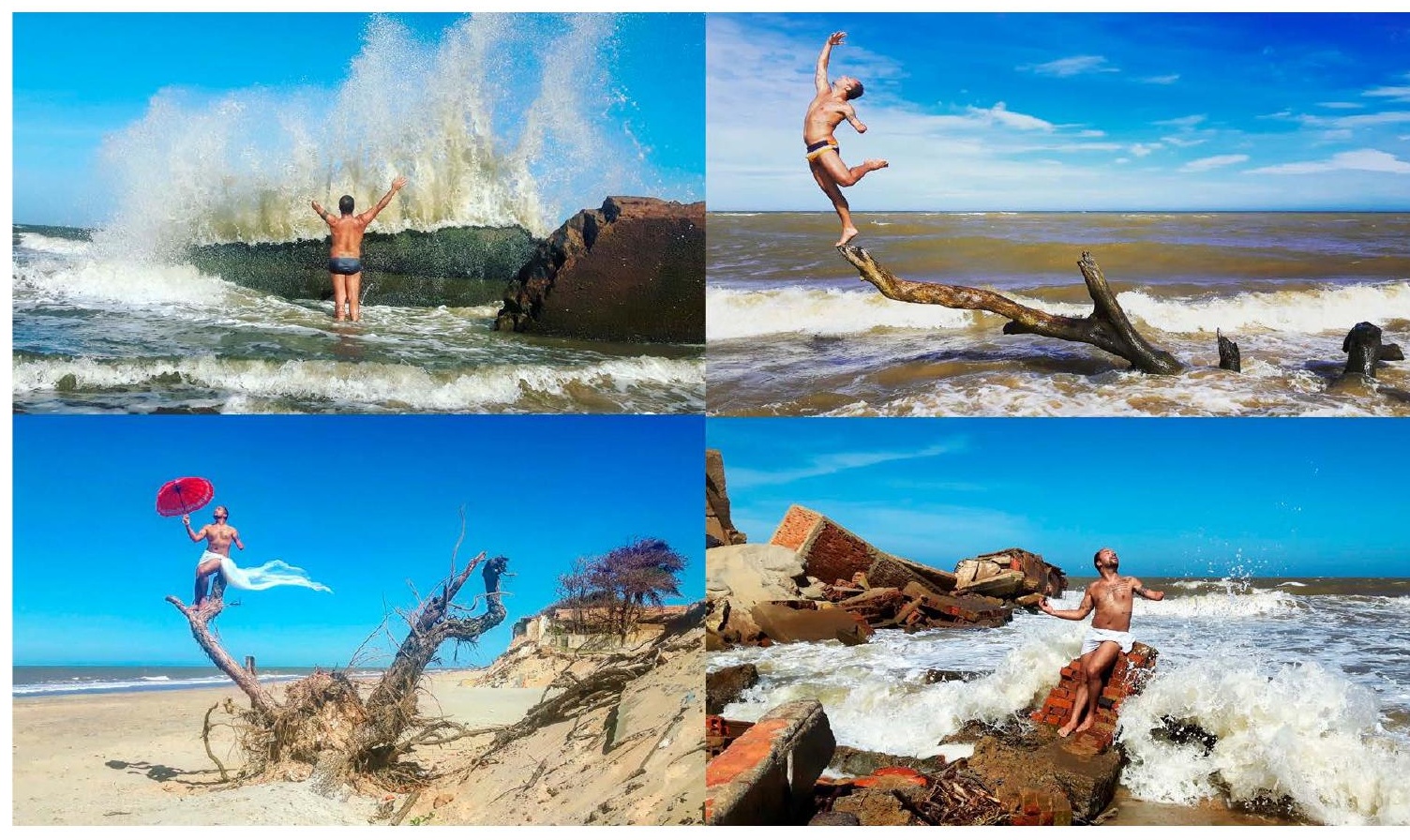

Para finalizar este breve relato de nossas experiências, gostaríamos de tecer algumas palavras sobre a proposição desenvolvida pela artista carioca Caroline Valansi durante a residência Erosões Visuais. Diferente de Anjo Amauri, Valansi possui uma sólida trajetória desenvolvida no campo das artes visuais. O seu trabalho nos chamou atenção pela escuta territorial afinada com as contingências de uma proposta de arte contextual. Durante a residência, que se deu em um espaço de tempo limitado, tivemos um período de intensas chuvas e fortes ventos, criando, aparentemente, uma situação de dificuldade para o trabalho de intervenções na/com a paisagem. A artista, no entanto, utiliza este aparente contratempo a seu favor, mobilizando a força do vento nordeste em dia de ressaca, através de uma enorme bandeira branca com um cabo de bambu de cinco metros de altura. Ao convidar os outros artistas e os curadores envolvidos na residência a sustentar erguida sua bandeira branca na região do pontal de Atafona, ela cria um jogo de resistência entre os corpos e o vento, uma verdadeira dança com a paisagem. Este trabalho nos remete aos parangolés de Hélio Oiticica, mas aqui encontra o diferencial de um confronto com a paisagem. Por outro lado, associamos também o trabalho às navegações a vela, mas aqui o símbolo da bandeira branca nos convida a um jogo poético com 
a paisagem, em um território em perpétua disputa entre os homens, os ventos, o mar e o rio. ${ }^{35}$

\section{Conclusão: Produção em distopia - entre ética, estética e política}

Acreditamos na potência do gesto de deslocamento operado por este trabalho, que visa inserir o "caso Atafona" em regimes de visibilidade e discursividade próprios dos meios artísticos e acadêmicos. Este ato, se bem-sucedido, poderá contribuir, por um lado, para articulação de uma rede de pesquisadores, artistas e ativistas que possam vislumbrar melhores políticas públicas para região. Por outro, o trabalho contribuirá também para a melhor compreensão de nosso problemático passado colonial e as implicações nefastas do projeto desenvolvimentista neoliberal em curso no Brasil. Entendemos que a visualidade desta cidade arruinada e continuamente se arruinando é a imagem real, desvelada em sua assustadora crueza, de tal projeto civilizatório. Ocorre que em Atafona se dá algo singular: como não há vítimas fatais do processo erosivo, nos permitimos sem grandes constrangimentos a apreciar a beleza imponente da paisagem do delta do Rio Paraíba do Sul. Esta beleza se expressa no vasto horizonte característico da planície, nas revoadas das gaivotas, no encontro das águas do rio e do mar, na gente simples e sorridente, nos manguezais sobreviventes e no vento úmido e prazenteiro.

Assim entre ruínas, escombros, troncos de manguezais mortos, vislumbramos uma natureza que apesar de tudo sobrevive. Esse tempo lento da erosão nos impõe uma sensação melancólica de perda do mundo. Quando andamos pelo que restou das ilhas da Convivência e do Peçanha, encontramos ruínas de casas, indícios de um mundo que desapareceu, o dos antigos moradores da ilha que tiveram que se deslocar para Atafona devido à subida do mar, formando uma pequena comunidade de refugiados ambientais que já não vive mais o mesmo mundo de outrora. Infelizmente, temos pouca esperança de que o processo erosivo pare e, se nada mudar no plano macro e micropolítico, a tendência é de que esta comunidade continue a viver, nas próximas décadas, este perpétuo deslocamento.

35 Fotos do trabalho de Caroline Valansi podem ser vistas no site da CasaDuna. 
Se é verdade que o mar chega e chegará para todos, ricos e pobres indiscriminadamente, é também verdade, que os meios para se reestruturar das perdas materiais causadas pelo desastre ecológico são e provavelmente continuarão sendo vertiginosamente desiguais. É neste sentido que entendemos a necessidade de pensarmos a herança de um passado colonial que se expressa hoje nos índices alarmantes de concentração de renda e terras no Brasil. Não podemos esquecer que o atual modelo de exploração do trabalho e acumulação do capital tem origens nos violentos processos coloniais, e que aqueles que se beneficiaram destes processos são os maiores responsáveis pelas mudanças climáticas hoje em curso. Como afirma Stengers:

A ideia de que isto que nós chamamos "progresso" não pode ser separada de uma
destruição ecológica, entendida como uma destruição de meios naturais, mas tam-
bém uma destruição social e mental, torna-se muito concreta. Eis uma das grandes
mudanças de perspectiva que vem com a ideia de um outro mundo possível. Este que
conhecemos é intrinsicamente tecido pela colonização, de uma demarcação e sec-
cionamento das terras colonizadas e da destruição e escravidão de seus habitantes. ${ }^{36}$

Assim, seguindo este raciocínio da filósofa Isabelle Stengers, estamos em um momento histórico em que um dado modelo de humanidade percebe os impactos de sua própria atuação sobre a terra como a inauguração de uma nova era geológica, qual seja, a do Antropoceno. No entanto, é preciso que critiquemos as afirmativas que fazem de um modelo civilizatório, que se tornou hegemônico, a totalidade universal e indiferenciada da espécie humana. O pressuposto segundo o qual "em um dado momento na História o ser humano virou uma força geológica" 37 exclui do conceito "ser humano" a experiência, por exemplo, dos povos indígenas, que em nada contribuíram para nosso ingresso na dita era do Antropoceno. E ao mesmo tempo, ao incluir toda a humanidade num único "nós", apaga-se as díspares responsabilidades históricas dos diferentes povos nas implicações catastróficas a que sofreremos todos. Ou seja, para usar uma fórmula bem conhecida, privatiza-se os lucros e socializa-se os prejuízos.

Consideramos que o abandono e a destruição são socialmente distribuídos, e são parte de um projeto de mundo, de uma política de exploração, extermínio e silenciamento, orientada por princípios de diferenciação 
racistas, classistas e coloniais. Existem cartografias da destruição e do abandono que sustentam o progresso e o investimento e que são a condição mesma da manutenção do status quo desenvolvimentista do ideário de modernidade, jamais realizado em territórios chamados "periféricos".

A denominação do Antropoceno, junto com o modo de vida que ela designa não pode desconsiderar a própria multiplicidade das cenas do humano em escala mais ampla da História e do planeta. Até porque - e este é o ponto que nos interessa frisar quando falamos em Antropoceno - não são todos os tipos de humano que têm o mesmo modo de relação exploratória com a Terra, e nem todos sofrem igualmente os efeitos dessa relação - como podemos ver em Atafona, sob nossos pés. Por isso, nos distanciamos desse uso comum, que considera "uma humanidade tomada como entidade biológica e como agente geológico". Na verdade, é justamente tentando expor fissuras deste ideário de "humanidade" associado aos humanismos do projeto europeu de Modernidade que a conceptualização subjacente ao trabalho da CasaDuna opera.

Acreditamos que a arte contemporânea pode ser uma ferramenta poderosa para provocar dissensos, fissuras, abalos nas estruturas epistêmicas, nos modos de produção e nos regimes de visibilidade institucionalizados. A crítica de arte Claire Bishop faz a seguinte observação:

o contemporâneo global é uma ficção compartilhada, o que não significa sua impossibilidade, mas ao invés, fornece as bases para um novo imaginário político. A ideia de que artistas podem nos ajudar a vislumbrar os contornos do projeto de repensar nosso mundo é certamente uma das razões pelas quais a arte contemporânea, apesar de sua quase total imbricação com o mercado, continua a despertar tanto interesse apaixonado e preocupação.38

Dizer que o comum é uma ficção não significa dizer que ele não exista, mas sim compreender que ele se constitui historicamente como resultante de um embate discursivo, do qual a voz que define o "nós" é, quase sempre, a dos vencedores. Inserida na temporalidade dos regimes estéticos e políticos, ela sempre se cria em uma copresença de diferentes discursos, dos quais uns são ouvidos e outros abafados, "as repartições do visível e do invisível", que silenciam ou menosprezam como "atrasadas" as múltiplas cenas do humano. 
O trabalho que fazemos leva em conta uma reflexão sobre a vida levada à precariedade pelas transformações ambientais, a relação entre a erosão geográfica e a "erosão" socioeconômica, para produzir um pensamento que vá além da catástrofe e da distopia. O trabalho é feito na perspectiva de compreender alteração nas possibilidades de desejo das pessoas que percebem estas ações, como uma espécie de contaminação que visa uma proliferação discursiva e um deslocamento epistemológico e político. Nas palavras de Gayatri Spivak:

(...) tornar visível o que não é visto pode também significar uma mudança de nível, dirigindo-se a uma camada de material que, até então, não tinha tido pertinência alguma para a história e que não havia sido reconhecida como tendo qualquer valor moral, estético ou histórico.39

Neste sentido, compreendemos nosso trabalho como um agenciamento político que se utiliza da arte contemporânea enquanto um campo múltiplo e relacional, como instrumento para estas ações. Mas, sobretudo, compreendemos o caráter existencial de nosso trabalho, uma vez que ele tem implicações diretas em nossas vidas, já que, no âmbito de nosso projeto, não há nenhuma exterioridade entre vida e arte. Não por acaso, o espaço da CasaDuna é a nossa própria casa.

\section{Referências}

AGAMBEM, Giorgio. Infância e história. Destruição da experiência na origem da história. [Trad. Henrique Burigo]. Belo Horizonte: Ed. UFMG, 2008. ARDENNE, Paul. Um art contextual - creation artistique en milieu urbain en situation d'intervention de participation. Paris: Ed. Flamarion, 2017.

BARBOSA, Aluysio Abreu. 2029. "Arthur Soffiati - Rio Paraíba do Sul morre em vão na poluição do Grande Rio » Folha 1.19 de Janeiro.

http://opinioes.folha1.com.br/2020/01/19/arthur-soffiati-rio-paraibado-sul-morre-em-vao-na-poluicao-do-grande-rio/. Acesso em 05 fev. 2020.

CUNHA, Juliana Blasi. 2007. «Atafona: Formas de sociabilidade em um balneário na região Norte-Fluminense. » Dissertação de Mestrado em An- 
tropologia. Niterói: UFF (Cunha, 2007).

BONNEUIL Christophe; FRESSOZ, Jean-Baptiste. L'Événement Anthropoce】ne. La Terre, l'histoire et nous. Paris: Seuil, 2013.

BRANTES, Eloísa. Foz afora - coletivo líquida ação, Rio de Janeiro: Wallprint, 2017.

DANOWSKI, Deborah; VIVEIROS DE CASTRO, Eduardo. Há mundo por vir? Ensaio sobre os medos e os fins. Florianópolis - Desterro: cultura e Barbarie, 2014.

FOSTER, Hall. O Retorno do Real. [Trad. Célia Euvaldo] São Paulo: Ubu Editora, 2014.

FOUCAULT, Michel. Le Courage de la a Vérité : Le gouvernement de soi e des autres II. Cours au collège de France (1984). Paris: Gallimard; Seuil, 2009.

GIACCO, Grazia. Recherche-création et didactique de la création artistique. Le chercheur travaillé par la création. Paris: EME Éditions, 2018.

LAMEGO FILHO, Alberto Ribeiro. A Terra Goytacá: à luz de documentos inéditos. Niterói: Diário Oficial, 1941, Vol. 5, s/p.

Magalhães, Noêmia. 2017. « Depoimento de Noêmia Magalhães. » In DIREITOS HUMANOS E EMPRESAS O caso do Complexo Portuário do Açu - RJ, Coordenado por Manoela Carneiro Roland. HTTP://HOMACDHE.COM/ INDEX.PHP/PT/DOCUMENTOS-SOBRE-EMPRESAS-E-DIREITOS-HUMANOS/. Acesso em: 05 fev. 2020.

MBEMBE, Achile. Necropolítica. [Trad. Renata Santini] São Paulo: N-1, 2018.

NETO, Arnaldo. 2018. « Dez anos de queda do prédio do julinho » Folha na Foz. 06 de Abril.http://www.folha1.com.br/_conteudo/2018/04/na_foz/1232489-dez-anos-de-queda-do-predio-do-julinho.html. Acesso em: 05 fev. 2020.

OLIVEIRA, Emiliano Castro de. 2015. « Mudanças na Sedimentação do Delta do Rio Paraíba do Sul nos Últimos 40 Anos: Resultados do Manejo Excessivo » O HOMEM E AS ZONAS COSTEIRAS - Tomo IV .

http://redebraspor.org/livros/2015/Braspor\%202015\%20-\%20Artigo\%2010.pdf. Acesso em: 05 fev. 2020.

PÁL PELBART, Peter. O avesso do niilismo - cartografias do esgotamento. São Paulo: N-1, 2017.

RIBERIO, Gilberto P., Figueiredo JR.,A. G. de, \& Rosas R. O. 2006 « processos costeiros: erosão em atafona e progradação em grussaí, são joão da barra (rj) - morfometria para retratação espacial desses eventos e identi- 
ficação de sua tendência evolutiva » IV Simposio nacional de Geomorfologia - 6 a 10 de setembro. http://Isie.unb.br/ugb/sinageo/6/6/288.pdf. Acesso em: 05 fev. 2020.

SPIVAK, Gayatri Chakravorty. Pode o subalterno falar? [Trad. Sandra R.G. Almeida, Marcos P. Feitosa, André P. Feitosa] Belo Horizonte: Editora UFMG, 2014.

STENGERS, Isabelle. Résister au désastre. Paris:Wildproject, 2019.

WISNIK, José Miguel. Maquinação do mundo Drummond e a mineração. Rio de Janeiro: Companhia das Letras, 2018.

Recebido em 19 de abril de 2020 e aceito em 02 de julho de 2020.

Este é um artigo publicado em acesso aberto sob uma licença Creative Commons (cc) $)$ 